\title{
O Partido Democrata Cristão no Brasil (1945-1963): (Re)considerações sobre sua breve existência
}

\author{
Christian Democratic Party in Brazil (1945-1963): (Re)considerations of its brief existence \\ El Partido Demócrata Cristiano en Brasil (1945-1963): (Re)consideraciones sobre \\ subreve existencia
}

Lorena Madruga Monteiro

\section{Resumo}

Os estudos sobre o sistema partidário brasileiro não consideraram o Partido Democrata Cristão como um elemento relevante na dinâmica partidária do período de 1945 a 1963 . A ausência desse Partido nas análises desse período democrático da política brasileira não desencorajou pesquisadores a considerarem o PDC importante nesse cenário, a exemplo dos estudos de Anselmo Coelho e Áureo Busetto. O primeiro ao comparar o caso chileno com o brasileiro mostrou como o PDC articulou-se com a categoria do populismo, e, é exatamente essa articulação que o diferenciou dos partidos conservadores. $\mathrm{O}$ segundo demonstrou que os membros do PDC brasileiro não advinham daqueles grupos representativos do movimento da Democracia Cristã (DC) o que explica sua pouca influência na arena eleitoral. Levando em conta os argumentos desses dois autores, este artigo buscou, por um lado, sistematizar os pressupostos de ambos sobre a trajetória do PDC no Brasil, para compreender porque a Democracia Cristã não obteve êxito no Brasil, como no Chile, e por outro, por meio da análise da dinâmica partidária e da trajetória do PDC em duas unidades subnacionais, objetiva-se demonstrar a necessidade de trabalhos de cunho monográficos sobre os partidos que refinariam as análises comparativas.

Palavras-chave: Sistema partidário. Partido Democrata Cristão. Democracia Cristã.

Doutora em Ciência Política pela UFRGS. Professora Titular I do Núcleo de Pós-Graduação em Ciências Sociais da Faculdade Integrada Tiradentes (FITs)

Recebido em 27/06/2012 - Aprovado em 14/09/2012 http://dx.doi.org/10.5335/hdtv.13n.2.3717 


\section{Introducão}

Os estudos sobre o sistema partidário brasileiro por um lado, o avaliam a partir de uma perspectiva negativa, como um caso de subdesenvolvimento partidário (LAMOUNIER \& MENEGHELLO, 1986; MAINWARING, 2001; AMES, 2003), e, por outro, demonstram uma série de relações nas quais as práticas partidárias brasileiras apresentam padrões representativos, como a relação legislativo-executivo (LIMONGI \& FIGUEIREDO, 1999) e a composição das coalizões governamentais (MENEGUELO, 1998; SANTOS \& AMORIN NETO, 2001), etc. No entanto, nenhuma dessas duas perspectivas incluiu o Partido Democrata Cristão no Brasil como um partido representativo no sistema partidário brasileiro durante o período de 1945 a 1964 . Para os primeiros sua curta duração, assim como a de outros partidos, revelava a fragilidade do sistema partidário, uma vez que os partidos não se enraizaram na sociedade. Para os segundos, como nesse curto período de tempo, o PDC nunca lançou candidato à presidência da República, o relacionamento desse partido com o executivo foi inexpressivo. Isso não desencorajou dois pesquisadores a considerarem o PDC durante sua curta existência importante. Refiro-me às pesquisas de caráter monográfico de Sandro Anselmo Coelho e de Áureo Busetto.

Anselmo comparou o caso chileno com o brasileiro e mostrou como em ambos os países o PDC articulou-se com a categoria do populismo ${ }^{1}$, e, é exatamente essa articulação, no caso brasileiro, que o diferencia de alguns partidos considerados conservado- res, principalmente da União Democrática Nacional (UDN). A visão do PDC como um partido satélite da UDN, foi, constantemente, enfatizada na literatura sobre partidos no Brasil sem uma avaliação mais detalhada até o trabalho de Coelho (2000). De outro modo, Busetto (2002), a partir das noções de campo, distribuição e reconversões de capitais de Pierre Bourdieu, preocupou-se em demonstrar que os partidários do PDC brasileiro não advinham daqueles grupos mais representativos da Democracia Cristã. Desse modo, além de distanciado da terceira via proposta pela DC, a legenda PDC foi composta por membros desvinculados da intelectualidade laica católica, apenas representando um espaço institucional para aqueles que queriam fazer carreira política no novo contexto democrático. Somente com a entrada do grupo Vanguarda Democrática (VD) que o PDC aproximou-se da DC e das propostas reformistas.

Levando-se em conta esses argumentos que analisamos, de forma geral, o PDC no Brasil, busca-se compreender a trajetória do PDC, por meio da apreensão dos seus pressupostos, e, como, embora o PDC tenha sido considerado um partido conservador alinhado à UDN (BENEVIDES, 1981; VIANNA, 1981; MENEGHELO, POWER \& MAINWARING, 2000), ao defender ideias mais reformistas conseguiu tornar-se uma alternativa política viável. Objetivamos com isso, de forma específica e preliminar, demonstrar a necessidade de mais trabalhos de cunho monográfico sobre os partidos no Brasil $^{2}$, uma vez que esses trabalhos centraram suas análises nos casos centrais (principalmente São Paulo e de forma superficial 
o Paraná), negligenciando os contextos federativos periféricos com tradições político-partidárias distintas daquelas (Rio Grande do Sul e Santa Catarina). Acredita-se, assim, que esforços interpretativos de tal escopo refinariam as análises políticas comparativas posteriores e enriqueceria a análise do nosso próprio sistema partidário.

\section{PDC no Brasil com base nos estudos existentes: do conservadorismo ao reformismo}

Os estudos sobre os partidos e a política brasileira no período de 1945 a 1964 não levaram em conta a importância que teve o Partido Democrata Cristão. Conforme Coelho (2000), o PDC foi o partido que mais cresceu no legislativo nacional entre 1954 até a adição do Ato Institucional n 2, em 1965. Estabeleceu-se significadamente no quadro político brasileiro, especialmente em 1962, no período da crise da democracia populista, como demonstra o seu crescimento no Congresso Nacional, quando salta de duas cadeiras em 1955 para 20, em 1962 ${ }^{3}$. Naquele momento, o PDC esteve em igualdade numérica com o Partido Social Progressista (PSP), fundado por Adhemar de Barros, que, em 1962, contava com 21 cadeiras.

Coelho (2000) argumenta que se houvesse regularidade no processo político eleitoral o PDC poderia tornar-se a quarta força política no legislativo nacional, o que foi abortado pela Ditadura Militar. Até porque o PDC esteve presente no executivo federal, primeiramente no Ministério da Previdência Social com André Franco Montoro no $1^{\circ}$ gabinete parlamentarista de Jango, e no Ministério de Educação e Cultura, com Paulo de Tarso Santos, no governo presidencialista de Goulart. Junta-se a esse fato a composição, coligados com a UDN, para eleger Jânio Quadros, antigo pedecista, à presidência da República, em 1960. Na esfera estadual o PDC conquistou o estado do Paraná, em 1960, com Ney Braga, e, em 1962 o estado de São Paulo, com Carvalho Pinto.

A Democracia Cristã, como se sabe, não se restringiu, enquanto movimento político, à realidade brasileira, tendo sido muito mais representativa em outros países, como o Chile, o que, possivelmente, levou Anselmo Coelho (2000) a empreender uma análise comparativa sobre os PDCs, surgidos nesses dois países por diferentes trajetos, tanto contextuais, como temporais. No Brasil, surgiu com a instauração do pluripartidarismo durante a democracia populista, de 1945 a 1964. A ascensão do PDC no Chile ocorreu quando Eduardo Frei Montalva chegou à presidência da República em 1964, frente ao projeto socialista de Salvador Allende.

A DC chilena teve uma trajetória mais antiga no Chile em relação à brasileira. Trata-se da Falange Nacional, criada pelo grupo de Eduardo Frei, após romperem com o Partido Conservador, em 1937. A partir desse momento a Falange participou de todas as eleições nacionais, até 1957, quando se juntou ao Partido Conservador Social Cristão, denominando-se PDC, cujo auge de seu trajeto foi a eleição presidencial de 1964, e, em 1965 , a conquista de $42,3 \%$ dos votos para as eleições parlamentares.

Considerando a trajetória da DC no Chile pode-se inferir que obteve mais su- 
cesso como uma alternativa política válida, enquanto a brasileira não galgou tanto êxito. Para Coelho (2000), a resposta não está ligada à ausência de um projeto de democracia cristã no Brasil anterior a instauração do multipartidarismo, porque, no contexto dos anos 1930 a 1940, os intelectuais católicos, juntamente com o clero, organizaram a Liga Eleitoral Católica (LEC), assim como divulgaram na revista $A$ Ordem a necessidade de organizar um Partido Democrata Cristão. No entanto, o PDC não foi criado pelos intelectuais católicos que organizaram a LEC e o periódico A Ordem no Rio de Janeiro, mas sim pelo grupo de São Paulo.

O PDC foi criado em 1945, em São Paulo, por Antônio Cesarino Júnior, professor de Direito do Trabalho na Universidade de São Paulo, e como o Partido Social Democrático (PSD) tinha o controle sobre as massas camponesas subalternas e o Partido Trabalhista Brasileiro (PTB) sobre as classes populares urbanas, acabou alinhando-se à UDN que articulava todos os oposicionistas de Vargas, só tendo alguma expressividade política em 1962. Nesse sentido, aproximou-se da DC chilena, que embora tenha surgido em 1937 com os líderes da juventude do Partido Conservador (Ignácio Palma, Jorge Rogers, Manuel Garretón, Eduardo Frei, Bernardo Leighton) que fundaram a Falange Nacional, apenas conseguiram ter expressividade nas urnas na década de 1950. Assim, quando o PDC chileno foi fundado, em 1957, já estava sintonizado, tanto com as propostas da terceira via da Europa e da América Latina, como com a sociedade chilena.

Essa aproximação, também, transparece no fato de que quando começaram a ter alguma expressividade, tanto o PDC chileno, quanto o brasileiro, combateram as reivindicações populares que não se acomodavam à ordem vigente. No caso do Brasil, os pedecistas alinharam-se à UDN e na conservação de suas propostas conservadoras, e os do Chile, quando estavam no governo, reprimiram as mobilizações populares, a exemplo da reação frente aos mineiros em El Salvador em 1966. No entanto, o governo chileno em certos aspectos adquiriu características populistas, como sua política de proteção social após ter enfrentado sucessivas crises econômicas com o objetivo de incluir os setores marginalizados da sociedade. $\mathrm{O}$ PDC brasileiro, diferentemente do chileno, só conseguiu se estabelecer politicamente com a crise da democracia populista, porque até então ele era entendido como um quadro auxiliar da UDN, assim como o Partido Libertador (PL) e o Partido Republicano (PR) (BENEVIDES, 1981).

Com o realinhamento partidário na década de 1950 o PDC brasileiro tornou-se uma alternativa reformista, especialmente dentre os pequenos partidos concentrados nos estados mais desenvolvidos, como São Paulo. No entanto, com o golpe de 1964 e a instauração do bipartidarismo em 1965, o crescimento do PDC foi interrompido. Entretanto, ao contrário do que argumenta Coelho (2000), à passagem PDC para uma postura reformista está mais relacionado à mudança na organização partidária com a inclusão de novos grupos refletindo-se nas reivindicações programáticas do Partido, do que apenas com o pouco espaço que este teve no período frente ao PSD e o PTB. Como tratamos a seguir. 
A organização partidária e o teor programático da "Terceira via brasileira"

Os programas e discursos dos pedecistas visavam responder duas conjunturas. Por um lado o contexto pós-1945, no qual submergiam novas formas de governo que teriam que substituir as medidas coercitivas do Estado Novo. Por outro, o início dos anos 1960, quando se configurou uma alteração no sistema partidário nacional com o declínio dos grandes partidos (UDN, PSD), que, com a crescente dispersão eleitoral, induziu o processo de realinhamento do sistema partidário no qual favoreceu os pequenos partidos reformistas, como o PDC.

Quando foi criado o PDC contava, em 1945, além do polo paulista, de Cesarino Júnior, com o pequeno Partido Popular, organizado pelo jornalista Osório Lopes, no Rio de Janeiro. O Partido era formado também por motivações ligadas à terceira via do Partido Popular Italiano, especialmente pelo desempenho eleitoral da Democracia Cristã no pós-2a guerra. Outro partido que se fundiu ao PDC brasileiro naquele contexto foi o embrião do Partido Republicano Democrático que foi formado em São Paulo, sendo composto por um reduzido número de membros que nutriam relações de amizade com as lideranças do Partido Popular (BUSETTO, 2002). Portanto, são esses os grupos que se alinharam em torno da terceira via cristã no Brasil.

Na conjuntura pós-1945 permaneceu um arcabouço institucional que controlava algum possível processo de aprofundamento da politização da sociedade brasileira, a partir da pouca alternância no poder entre o PSD e o PTB, à exceção do governo de Jânio Quadros, e, desse modo, o PDC não teve grandes espaços para apresentar-se politicamente, só tendo alguma expressividade na década de 1960. Outro elemento que dificultou uma maior expressividade do PDC foi à recusa da Igreja Católica em apoiar o Partido. Portanto, diante desse quadro o número de pedecistas no Congresso Nacional não foi significativo ${ }^{4}$.

Nesse contexto, os pressupostos dos pedecistas estiveram em sintonia com aqueles que pretendiam reorganizar o sistema político brasileiro, ou seja, os partidos contrários ao que o Estado Novo representou. Assim as reivindicações do PDC naquele contexto eram: uma nova Constituição democrática, a supressão do Departamento de Imprensa e Propaganda (DIP) e do Tribunal de Segurança Nacional, assim como a revogação das leis de opressão. As suas propostas consistiam na instauração do sufrágio universal e a autonomia e respeito mútuo entre os poderes.

Possivelmente, como argumenta Coelho (2003), essa oposição à Vargas tenha feito com que Benevides (1981) e Vianna (1981) denominassem o PDC como uma UDN católica. Realmente, essa associação tem fundamento, porque, durante o governo Juscelino Kubitschek os pedecistas estiveram próximos da linha de atuação de Carlos Lacerda, e, dessa forma, articulavam-se com a elite política que ambicionava conduzir os rumos da abertura democrática. Por outro lado, no programa do PDC de 1945, advertiam que a ascensão das massas seria benéfica para a democracia, desde que repousadas sobre uma base ética racional e evangélica. Por- 
tanto, conforme demonstrou Coelho (2003) a participação popular na política e a própria democracia teria um caráter positivo se condicionadas à existência de um ordenamento evangélico na sociedade. O medo dos pedecistas naquele momento era que as massas populares se organizassem de forma que colocasse em risco o reordenamento político. Isso remete a um forte sentimento anticomunista dos membros do PDC, o que também era compartilhado pelos representantes da UDN, como Carlos Lacerda.

No campo econômico o PDC demonstrava uma ambiguidade programática. Por um lado mostrava-se claramente liberal, ligando-se às propostas da UDN, e, por outro, indicavam a necessidade de intervenção estatal no mundo econômico. Desse modo, eram liberais quando defendiam que estado não podia interferir nas atividades econômicas privadas, a não ser temporariamente, $\mathrm{e}$ na defesa da intervenção da política internacional para evitar a todo modo o protecionismo nacionalista. E eram intervencionistas quando defendiam a ação estatal na economia limitando os lucros das empresas, aproximando-se, assim, da terceira via dos países europeus.

No contexto da década de 1960, com o realinhamento partidário, o PDC mostrou-se mais afinado com a democracia cristã internacional. A partir desse momento o PDC pulou de duas cadeiras para 20 e conquistou uma no Senado. Um dos fatores que contribuíram para isso foi a entrada, na década de 1950, de militantes advindos da Vanguarda Democrática (VD), de São Paulo. A VD era composta por democratas cristãos fundamentados no pensamento de Jacques Mari- tain $^{5}$, e que mantinham relações com outros partidos democratas cristãos na América Latina. Nesse sentido, Coelho (2003) e Busetto (2002) entendem que a VD ao entrar no PDC buscou dar um caráter mais programático a sua ação católica.

A VD era composta por militantes que atuaram na Ação Católica Brasileira e na Juventude Universitária Católica (JUC), como Franco Montoro, Antônio Queiroz Filho, Plínio de Arruda Sampaio, Chopin Tavares de Lima, João Baptista de Arruda Sampaio, Teófilo Ribeiro de Andrade Filho, Eduardo Bastos, Luís Melo, Nader Gouvêa, Helena Junqueira, Odilon da Costa Manso e Clóvis Garcia. É importante destacar que Franco Montoro havia participado, juntamente com o líder católico do Centro Dom Vital Alceu Amoroso Lima ${ }^{6}$, do I Congresso da Democracia Cristã na América ${ }^{7}$, realizado em Montevidéu.

Outro fator que contribuiu para o crescimento do PDC, além da mudança na organização partidária com o ingresso da $\mathrm{VD}$, foram os problemas que a elite política defrontou-se no início da década de 1960. Desse modo, como temas controversos entraram na agenda política com o esgotamento do modelo de desenvolvimento no final do governo Juscelino, os partidos foram forçados a terem funções ideológicas mais claras, como foi o caso do PDC. Sendo assim, o PDC cresceu em sintonia com a abertura do mercado brasileiro ao capital monopolista internacional. Foi nessa conjuntura que Carlos Lacerda, líder da UDN, quis ingressar no PDC, mas com a resistência da VD não entrou. 
Foi exatamente nesse momento que as ideias da VD foram bem posicionadas no PDC. E assim o PDC modificou seu programa frente à nova agenda brasileira, em sua Convenção Nacional, em 1961. Na convenção, três linhas se confrontaram: a conservadora, a reformista e uma mais moderada. A conservadora - cujos maiores representantes foram Arruda Câmara e Juarez Távora - defendia a moralização dos processos de administração pública, era anticomunista e avessa às reformas. A ala reformista, representada por Paulo de Tarso Santos, Plínio de Arruda Sampaio e pela Juventude Democrata Cristã (JDC), defendiam o nacionalismo econômico e o caráter anti-imperalista da terceira via. Esse grupo propunha reformas sociais, como a agrária, que melhorassem as condições dos trabalhadores urbanos e rurais. Chegaram inclusive, liderados por Paulo de Tarso, a proporem a mudança da sigla PDC para "Partido Socialista Cristão". O terceiro grupo, mais moderado, representado por Antonio Queiroz Filho e Franco Montoro, defendia as reformas, mas distante do anticomunismo, assim como da busca do socialismo. Foi exatamente esse grupo o agente conciliador da convenção, e, assim, a formulação da terceira via acomodou as demandas de cada tendência.

Portanto, a partir desse momento ficaram mais explícitas as propostas da terceira via voltadas para as reformas estruturais. Possivelmente, como deduz Coelho (2003), influenciados pela Escola cepalina ${ }^{8}$, defenderam os países subdesenvolvidos e chegaram até a propor a composição de um bloco de países latino-americanos voltados contra a opressão do imperialismo, assim como a de- fesa da igualdade entre os estados nacionais na ONU, contra o direito de veto das grandes potências. Desse modo, o PDC aliou-se ao reformismo de João Goulart, afastando-se do objetivo de uma ordem social calcada na evangelização e na hierarquia para a defesa de uma democracia institucional de proteção dos grupos sociais intermediários, como o município, o sindicato, a empresa, a escola, ou seja, exatamente os entes que não podem ser absorvidos pelo estado ou eliminados. Também, advogaram em torno da necessidade de reformulação do sistema eleitoral com o objetivo de evitar que os grupos econômicos influenciassem na política por meio dos financiamentos privados.

Todas essas propostas reformistas tomaram corpo na convenção do Partido em 1963, na qual o grupo de Paulo de Tarso e Plínio Arruda Sampaio conseguiram eleger Ney Braga como presidente nacional do Partido, por entenderem que o governador do Paraná estava mais apto a aceitar suas ideias reformistas, do que Franco Montoro. É exatamente nesse momento que a terceira via do PDC aproximou-se do movimento internacional "Economia e Humanismo" do Padre francês Louis-Joseph Lebret ligado à Análise Gráfica e Mecanográfica Aplicada aos Complexos Sociais (SAGMACS). Esse movimento tinha por base agir na periferia do capitalismo para erradicar os excessos do populismo e do capitalismo por intermédio de projetos de planejamento.

Na câmara dos deputados a representação do PDC aumentou, uma vez que na legislatura de 1959-1963 figuravam os nomes de Arruda Câmara, Paulo de Tarso Santos, Franco Montoro, Geraldo Corrêa de Carva- 
lho, José Menck, Ney Braga, Etelvino Lins. Portanto, o PDC tentou firmar sua terceira via no quadro político nacional de maneira independente dos três grandes partidos, como exemplo, a coligação que firmou com o PR, PTN, PSB. Assim, essa aliança demonstra que eles podiam alinhar-se a outros partidos, até aqueles que se entendiam como socialistas. Desse modo, nesse momento não podiam mais ser considerados uma ramificação da UDN porque agiam de forma independente.

No entanto, isso não isentou os membros de práticas políticas ambíguas em relação ao programa programático do Partido. Por exemplo, o programa era contrário ao financiamento de campanhas eleitorais por parte de empresas, e muitos dos membros do PDC foram ligados a Ação Democrática Popular do Instituto de Pesquisas e Estudos Sociais e o Instituto Brasileiro de Ação Democrática (IPES/IBAD). Foram exatamente esses dois institutos que agiram contra o governo nacional-reformista de João Goulart e contra as forças que o apoiavam. Alguns dos membros do PDC financiados foram: Ney Braga, Gadstone Chaves de Mello, o sindicalista Rômulo Marinho, Gabriel Chaves de Mello, Euclides Triches e Juarez Távora e Carvalho Pinto.

Fora esse fato, ao aliar-se a um discurso reformista, o PDC construiu sua expressividade na política brasileira, sendo uma alternativa política viável. Desse modo, o argumento de Vianna (1981, p. 135), de que: "A proposição da terceira via do PDC não se pautou pelo reformismo e, ademais, não se empenhou como um projeto modernizante, tendo cumprido um papel social pra- ticamente inócuo" torna-se equivocado. No entanto, deve-se saber a qual grupo do PDC Vianna referia-se.

\section{0 recrutamento político e o insucesso do Partido Democrata Cristão no Brasil}

Para Busetto (2002, p. 16), esse equívoco de Vianna está relacionado ao fato que ele "não distingue a história propriamente da formação e desenvolvimento da Democracia Cristã no Brasil da História do PDC". O grupo fundante do PDC, nessa perspectiva, não teve nenhuma ligação com a DC, como argumenta Busetto o PDC surgiu:

Da reunião de políticos, funcionários públicos, alguns poucos religiosos e militantes do catolicismo social que, anteriormente ligados ao Estado Novo e sem obterem o espaço político desejado nos dois partidos engendrados por Getúlio Vargas, procuraram valer-se da emblemática sigla partidária, na época em ascensão na Europa ocidental, para participarem do jogo político eleitoral nacional e tentarem ver atendidos os seus interesses políticos pessoais (2002, p. 17).

Esse foi um dos fatores que explicam porque o PDC até a década de 1950 não se transformou numa alternativa política, ao contrário do grupo do Eduardo Frei no Chile. Para Áureo Busseto (2002), o autêntico grupo democrata cristão no país foi a VD, que, como frisamos acima, após entrar no PDC, realinhou seu programa em torno de propostas reformistas. A VD era composta por membros oriundos da Juventude Universitária Católica, orientados por religiosos dominicanos. Com a impossibilidade dos próprios organizarem um projeto da 
DC, tanto pela recusa da hierarquia católica, quanto pela falta de experiência de prática política dos membros, o movimento democrata cristão em formação não pode conquistar os setores católicos de base popular, e desse modo, tudo isso os levou a entrarem no PDC, conforme demonstra Busetto:

Os democratas cristãos atendendo os apelos do Pe. Lebret, que mantinha proximidade com o movimento e recomendava a atuação direta junto às massas populares, e influenciados pela acentuada vocação política de Franco Montoro, então confirmando sua liderança no grupo, passaram a considerar a alternativa de ingresso num Partido Político para tornar sua militância mais efetiva. Amadurecida a ideia, os militantes do Vanguarda Democrática ingressariam no PDC e passariam a se ocupar mais decididamente com a estruturação do movimento democrata-cristão como uma força política- partidária (2002, p. 65).

Anteriormente ao ingresso da VD ao PDC, na década de 1950, com a saída de Cesarino Júnior e seu ingresso no PTB, Arruda Câmara assumiu a presidência do PDC e imprimiu um exacerbado anticomunismo que se refletiu nas eleições de 1947 nas quais o PDC teve um desempenho insatisfatório. E ao apoiar o Brigadeiro Eduardo Gomes da UDN, e não Getúlio Vargas, o PDC aliou-se à UDN, embora, nunca tenha incluindo em suas proposições uma discussão aprofundada sobre o Varguismo e o trabalhismo. Segundo Busetto, naquele período a lógica interna do PDC estava calcada entre o conservadorismo e o clientelismo político, como abaixo:

De um lado, Monsenhor Arruda Câmara contando com o apoio da maioria dos membros da direção nacional do PDC e; sobretudo, valendo-se de seus capitais políticos, cultural e religioso mantinha-se mais bem posicionado no controle partidário e facilmente desvirtuava a ideologia que presidiu a constituição do partido, procurando conduzi-lo na linha confessional como o verdadeiro defensor da moral católica e o firme vigilante anticomunista. De outro, grande parte dos membros do PDC ingressava nas fileiras do partido unicamente para valer-se da legenda para disputar eleições ou barganhar seu apoio com os núcleos decisórios do poder em troca de favores pessoais. Desses políticos, a direção nacional do PDC, centralizada na figura de Arruda Câmara e com o estatuto do Partido a seu favor, apenas exigia que fossem católicos e anticomunistas, medida que ao mesmo tempo criava uma aparente unidade de interesses ao Partido e permitia a convivência de duas tendências sem conflitos (2002, p. 83).

Em meados da década de 1950 e início da década de 1960, o PDC alinhou-se ao discurso reformista. E isso está relacionado, segundo Busetto (2002), à entrada da VD que pretendiam imprimir uma linha mais próxima da DC e impedir que a participação política do PDC continuasse meramente eleitoreira. Embora a adesão à candidatura de Jânio Quadros à presidência da República apoiada por Ney Braga e Paulo de Tarso fosse vista com uma estratégia do PDC de alcançar o poder, não consistiu num ato consensual entre os membros. Para tanto, Jânio teve que aprovar o programa mínimo do PDC, que naquele momento, já estava modificado, e, consistia em propostas de reformas, como a agrária e a reforma da estrutura da empresa privilegiando a participação dos trabalhadores na direção e no lucro.

Para Busetto (2002, p. 161-162), o apoio à candidatura de Jânio não significou uma ligação mais consistente com a UDN, 
pelo contrário, "demonstrava assim sua intenção de passar por cima da exclusividade cedida à UDN para lançar candidato a vice-presidente dentro da coligação partidária que apoiava Jânio", uma vez que apoiou o ex-petecista gaúcho Fernando Ferrari do TEM para concorrer ao cargo.

Após a conturbada campanha de Jânio e suas posições divergentes em relação à política, destacaram-se duas lideranças da tendência cristã nacionalista-reformista, com influência sob a Juventude Democrata Cristã: Plínio de Arruda Sampaio e Paulo de Tarso. Esses foram atacados por Carlos Lacerda por apoiarem o governo revolucionário cubano. Com a renúncia de Quadros, esse grupo aproximou-se de João Goulart por meio de Ney Braga que havia lutado pela legalidade da posse de Jango junto com Brizola. Essa ligação teve como resultado que Franco Montoro assumiu o Ministério do Trabalho e da Previdência Social, pasta tradicionalmente ocupada pelo PTB, no governo parlamentarista de Jango.

Pode-se compreender a inclusão do PDC no gabinete parlamentarista como uma opção de Jango de distribuir o gabinete entre vários partidos, não compondo um governo partidário. Entretanto, a partir de uma efêmera ligação do PDC ao PTB no combate às campanhas conservadoras contra as reformas de base, e da neutralização da ala conservadora do PDC, dois membros foram nomeados para o Ministério presidencialista de João Goulart: Paulo de Tarso, para a pasta da Educação, e Carvalho Pinto, para a da Fazenda. Contudo, conforme Busetto:
Carvalho Pinto e Paulo de Tarso não seguiram as diretrizes do PDC durante o efêmero período em que participaram do Governo Goulart. O primeiro não era um Democrata Cristão e sua nomeação em hipótese alguma tinha sido motivada em virtude de sua filiação partidária. Já o segundo, que assumira o Ministério da Educação apenas com o apoio parcial do PDC, preferiu pautar-se por uma postura de esquerda [...] $(2002$, p. 214).

Com o acirrado movimento contra as reformas de base de Jango, a ala conservadora do PDC tentou de todas as formas desvincular o Partido do esquerdismo e das posições de Paulo de Tarso e de Plínio de Arruda Sampaio. No entanto, conforme demonstrou Busetto (2002), nenhum dos agrupamentos democratas cristãos opunha-se às reformas de base e as propostas do programa de 1963, porque elas posicionavam melhor o PDC na competição com os demais partidos, mas todos os grupos, em detrimento aos membros mais à esquerda, indicavam que quem deveria conduzir o PDC para a sua rota político-partidária original eram: Juarez Távora, Franco Montoro ou Queiroz Filho e Ney Braga. Exatamente as lideranças com posições mais de centro-reformista.

Anteriormente ao golpe, essas lideranças começaram a afastar-se do governo Jango. Com o golpe, antes de terem seus direitos políticos cassados, Paulo de Tarso e Plínio de Arruda Sampaio manifestaram seu apoio contra a deposição do Jango. A linha centro-reformista, por sua vez, evitou posições mais apressadas consequente da situação de desconforto que se encontrava com a participação do governador Ney Braga, presidente do PDC, no movimento golpista e pela adesão de Juarez Távora ao nascen- 
te governo militar. E o PDC, liderado por Franco Montoro na câmara dos deputados, acabou apoiando a candidatura única de Castelo Branco.

Com a vitória presidencial de Eduardo Frei no Chile, a facção centro-reformista da PDC brasileiro teve que admitir o quanto as "contradições de suas práticas políticas tinham deixado aberto o caminho para Ney Braga e Juarez Távora imprimirem ao PDC uma postura calcada num misto de oportunismo e conservadorismo, descaracterizando a rota político-ideológica pretendida pelo partido e que parecia então alcançada pelo notável militante chileno da Democracia Cristã" (BUSETTO, 2002, p. 228). Já o grupo nacionalista-reformista, de Paulo de Tarso e Plínio de Arruda Sampaio, durante a ditadura militar no Brasil exilaram-se no Chile e trabalharam na experiência de reforma agrária do governo de Eduardo Frei e na Organização das Nações Unidas para Alimentação e Agricultura.

Portanto, com a instituição do bipartidarismo, em 1965, o PDC e suas facções desintegraram-se, tendo alguns membros se aliado à defesa do regime militar na ARENA, e, outros, na oposição, por meio do MDB. Para Busetto (2002) o fracasso do projeto de Democracia Cristã no Brasil está relacionado ao fato que o minoritário grupo nacionalista-esquerdista não conseguiu manter uma coesão partidária em torno do seu projeto de atualização da DC. Desse modo, mesmo que o contexto da década de 1960 tenha aproximado o PDC em torno de ideais reformistas e populistas como demonstrou Coelho (2000, 2003), o recrutamento dos membros, as práticas controversas, assim como as lu- tas intrapartidárias definiram o insucesso da Democracia Cristã no Brasil.

\section{Consideracões finais}

\author{
Notas sobre o PDC no Rio Grande do Sul \\ e em Santa Catarina
}

A crítica de Anselmo Coelho (2000, 2003) à tese de doutorado de Áureo Busetto (2002) é que este baseou seu trabalho no PDC paulista. No entanto, ao analisar mais detalhadamente, ambos os trabalhos centraram suas análises nos casos paulista e paranaense. É claro que foram nesses estados que o PDC foi mais expressivo e por isso encontram-se mais dados. No entanto, seria importante uma pesquisa mais detalhada nos casos em que a UDN não teve expressão como oposição ao populismo, como o caso do Rio Grande do Sul, e naqueles em que o PTB teve uma atuação inexpressiva, como em Santa Catarina.

Em ambos os estados federativos os grupos fundadores do Partido advinham das Congregações Marianas dos Colégios Jesuítas (Catarinense em Florianópolis, e Anchieta em Porto Alegre), e da Ação Católica. No entanto, enquanto o PDC do Rio Grande do Sul demorou a formar-se porque os líderes da intelectualidade católica já se encontravam nos Partidos existentes ${ }^{9}$, o PDC em Santa Catarina foi fundado em 1946 por aproximadamente 30 líderes católicos ligados à Congregação Mariana Nossa Senhora do Desterro ${ }^{10}$. Contudo, na sua primeira experiência eleitoral, embora seu candidato à vereança Ari Silva tenha sido o mais votado, assim como caso de Harry Bauer para De- 
putado Federal, o PDC não atingiu o quorum eleitoral para fazer frente à tradicional dominação política das famílias Ramos (PSD), Konder e Bornhausen (UDN).

Dada essa configuração política o PDC de Santa Catarina, num primeiro momento, apoiou Irineu Bornhausen (UDN) ao governo do estado, e com isso seus líderes passaram a ocupar cargos na administração estadual. O PDC passou a ter uma maior visibilidade, em 1954, ao eleger vários vereadores e alguns prefeitos e seu primeiro Deputado Estadual Rubens Nazacieno Neves, reeleito, em 1958. Portanto, nesse momento, atuaram como um apêndice da UDN, confirmando as proposições de Vianna (1981) sobre o papel do PDC no Brasil. Situação que se altera a partir de 1958, com os embates em relação à posição do PDC frente a possíveis coligações. Isso gerou o escândalo das procurações falsas na Convenção do Partido, em 1960, quando se discutia a sucessão estadual. Segundo Lenzi (1983, p. 190), essa questão estaria relacionada à mudança no perfil dos partidários, uma vez que:

A briga teria surgido em decorrência da infiltração de cristãos novos em busca da legenda para a Assembleia Legislativa, muitos deles forçando coalizões (com o PSD ou com a UDN) para a Câmara Federal, e arrumações municipais em torno de interesses personalísticos.

De todo modo, embora tenha lançado Martinho Callado Júnior numa candidatura independente para vice-governador, no pleito de 1960, assumiu uma coligação com o PSD. Nesse mesmo período, elegeram o Prefeito de Campo Alegre, e, em 1962 dois Deputados estaduais. Dessa forma, o PDC em Santa Catarina, embora formado por lideranças católicas, dada a configuração política do estado não conseguiu imprimir um projeto calcado nos princípios do movimento democrata cristão, coligando-se e representando um braço conjunto com os dois Partidos conservadores e forças políticas do estado, a UDN e o PSD.

Para Lenzi (1983: 191) isso se relaciona com a problemática levantada por Busseto (2002), porque seu insucesso deve-se, além da questão da figuração política do estado, à mudança no recrutamento dos membros, uma vez que: “Até sua extinção em 1966, o Partido Democrata Cristão pouco evoluiu, tendo servido de massa de manobra de alguns políticos fisiológicos, mesmo porque, os chamados democratas cristãos tradicionais, já vinham se afastando da nave desde 1962" (LENZI, 1983, p. 191).

O caso do Rio Grande do Sul apresenta especificidades em relação à dinâmica do PDC em Santa Catarina. Sua pouca expressividade deveu-se mais a tradição política do estado do que a questão do recrutamento partidário. Embora o grupo idealizador do PDC no RS - Fernando Gay da Fonseca, José Sperb Sanseverino, Edmundo Casado Marques, Fernando Costa Gama, Cid Furtado, Julio de Rose, Jorge Azevedo - representassem uma ramificação mais jovem da intelectualidade católica advinda das Congregações Marianas e da Ação Católica e contassem com o apoio dos políticos católicos não conseguiram arregimentar essas personalidades para a criação da nova sigla.

Dado esse primeiro empecilho na formação de seus quadros o PDC só foi organizado e fundado em 1953. Desse modo, surgiu no contexto da crise da democracia 
populista e da ascensão do PTB. Na sua primeira eleição, em 1954, não elegeu nenhum candidato, mas em 1955 o PDC conquistou duas cadeiras no Legislativo gaúcho, uma com José Alexandre Zacchia ${ }^{11}$ e outra com Mário Mondino. No entanto, naquele momento, o PDC assumiu uma posição de neutralidade em relação às candidaturas ao governo do estado que representavam à coligação do Trabalhismo cujo candidato vencedor foi Leonel Brizola, contra a frente democrática de Walter Peracchi Barcellos.

Contudo, sua posição de neutralidade dura pouco, porque nas eleições para a prefeitura de Porto Alegre, em 1959, o PDC lançou junto com o PL a candidatura vitoriosa de Loureiro da Silva, dissidente do PTB, contra o candidato do PTB Wilson Vargas. Nesse momento, o PDC gaúcho apareceu entre os três Partidos mais importantes da capital ao conquistar três cadeiras na Câmara Municipal. Conforme depoimento de José Sperb Sanseverino:

Na eleição municipal de 1959, o partido começou a alcançar uma projeção maior. $\mathrm{O}$ Dr. Loureiro da Silva aceitou ser candidato pela legenda do Partido Democrata Cristão com o apoio do Partido Libertador. Com esse candidato, pela sua projeção e pelo nome que já deixara gravado na história de Porto Alegre, foi-nos possível conquistar a Prefeitura de Porto Alegre e eleger na bancada do PDC três vereadores, o Leônidas Xausa, o Milton Krauser e eu. Aí então começamos a influenciar decididamente à vida política da cidade (2005, p. 137).

Porém, foi no pleito para governador, em 1962, que definiram sua posição como oposição ao PTB, ao coligar-se com o PSD, o PL, a UDN, e o PRP na Ação Democrática Popular em torno da candidatura Ildo Mene- ghetti (PSD), eleito. Portanto, o PDC definiu-se, no Rio Grande do Sul, por oposição ao PTB e ao reformismo. No entanto, isso também foi decorrente do espectro político - ideológico do Rio Grande do Sul e porque o PDC, enquanto mantinha-se numa posição neutra, não se aproveitou da ligação que estabeleceu com Loureiro da Silva e seu vice Fernando Ferrari nas eleições de 1958 mantendo-os no PDC. Desse modo, Ferrari acabou levando seu reformismo trabalhista para o MTR, o qual criou seu próprio espaço e empurrou:

Novamente o PDC ao encontro dos Partidos conservadores tradicionais do Estado, os quais se une para formar a ADP, em 1962. Portanto, diferentemente do que ocorre com o PDC paulista, onde um grupo (mais jovem) acaba assumindo uma posição francamente reformista, no Rio Grande do Sul esse espaço já estava, por assim dizer, ocupado (CÁNEPA, 2005, p. 382).

Um dos fatores que demonstra que o PDC gaúcho não teve ligação com as propostas reformistas foi que ele cresceu eleitoralmente agregando os votos do PSD, PL, UDN e PRP, não tendo assimilado os do PTB, que possivelmente foram para o MTR. Dessa forma, conforme demonstrou Cánepa (2005) houve certa continuidade de sua posição ideológica uma vez que, com a instituição do bipartidarismo, dez membros do PDC ingressaram na ARENA, e apenas três no MDB. Outro aspecto foi à renúncia do líder católico rio-grandense Armando Câmara, eleito pelo PDC e pela Ação Democrática Popular ao Senado, em 1955, após General Lott ter conduzido ao poder Juscelino Kubitschek e João Goulart, porque não se submetia a ficar num congresso nacional de um governo que não considerava legítimo. 
De todo modo, os casos brevemente delineados do Rio Grande do Sul e de Santa Catarina distanciam-se do caso paulista, especialmente das propostas da Vanguarda Democrática. Entretanto, não inviabiliza as generalizações feitas nas análises de Busetto (2002) e Coelho (2000, 2003), até porque, na falta de um estudo mais aprofundado sobre a Democracia Cristã e o PDC no Sul do país é impossível saber se os grupos que fundaram o Partido tinham ligações com o movimento internacional e os pressupostos da Democracia Cristã. Por isso, é importante que sejam feitos mais estudos de casos partidários, tanto centrais, quanto periféricos, para que futuramente possam-se agregar dados consistentes para o desenvolvimento da política comparativa.

\section{Abstract}

Studies on the Brazilian party system ignore the Christian Democratic Party as a relevant element in the period 1945-1963. The absence of this party in the analysis of the democratic period of Brazilian politics, has not discouraged researchers to consider the PDC important in this scenario, as studies of Anselmo Coelho and Áureo Busseto. The first to compare the Chilean case with the Brazilian showed that the PDC was associated with the category of populism and, exactly is this articulation that differed from the conservative parties. The second showed that members of the PDC did not come from groups representing the Christian Democratic movement, which explains their lack of influence in the electoral arena. Having regard to the arguments of these two authors, this article aims, first, systematizing the assumptions of both authors on the trajectory of the PDC in Brazil, and, secondly, to analyze the dynamics of the PDC in two sub-national units, with to demonstrate the need for monographs on political parties to deepen the comparative analysis.

Keywords: Partisan system. Christian Democratic Party. Christian Democracy.

\section{Resumen}

Los estudios sobre el sistema partidario brasileño no consideran el Partido Demócrata Cristiano como un elemento relevante en la dinámica partidaria del periodo de 1945 a 1963. La ausencia de este Partido en las analices de este periodo democrático de la política brasileña no desalentó investigadores a consideraren el PDC importante en ese escenario, a ejemplo de los estudios de Alselmo Coelho y Áureo Busetto. El primer comparando el caso chileno con el brasileño mostró como el PDC se articuló con la categoría del populismo, y, es exactamente esa articulación que lo diferenció de los partidos conservadores. El segundo demostró que los miembros del PDC brasileño no provenían de aquello grupos representativos del movimiento de la Democracia Cristiana lo que explica su poca influencia en la arena electoral. Teniendo en cuenta los argumentos de eses dos autores, este artículo buscó, por un lado, sistematizar las suposiciones de ambos los autores sobre la trayectoria del PDC en Brasil, para comprender porque la Democracia Cristiana no obtuve éxito en Brasil, como en Chile, y, por 
otro, través del analice de la dinámica partidaria y de la trayectoria de PDC en dos unidades sub nacionales, se objetiva demonstrar la necesidad de investigaciones de cuño monográfico sobre los partidos que refinarían los analices comparativos.

Palabras-clave: Sistema partidario. Partido Demócrata Cristiano. Democracia Cristiana.

\section{Notas}

1 Sandro Anselmo Coelho (2000) ao realizar seu estudo comparativo sobre a Democracia Cristã no Chile e no Brasil trabalha com a categoria de populismo desenvolvida por Octávio Ianni na obra A formulação do estado populista na América Latina, a qual, para sua compreensão, requer que "relacionemos às crises do capitalismo mundial que colocaram em xeque, na América Latina, o modelo de exportação primária, seja ele envolvido com a agricultura, com a pecuária ou com a mineração. Tal processo acarretaria fortes tensionamentos políticos entre os diversos grupos sociais que visam a assumir o controle do estado, que não pode mais ser conduzido apenas pela oligarquia exportadora. Todavia, nenhum dos grupos sociais tradicionais teria possibilidade de, sozinho, realizar tal tarefa, sendo necessária uma aliança com os setores sociais emergentes" (COELHO, 2000, p. 74).

2 Para o período considerado (1945-1964) encontram-se excelentes estudos monográficos sobre os três principais Partidos, como o de Benevides (1981) sobre a UDN; o de Hippólito (1985) sobre o PSD e o de D'Araújo (1996) sobre o PTB.

3 Foram eleitos para o Congresso Nacional em 1962: José Werneck (BA), Juarez Távora (GUA), Francisco Accioly Rodrigues da Costa Filho (PR), Emílio Hoffmann Gomes (PR), José Richa (PR), Minoro Myamoto (PR), Arruda Câmara (PE), Geremias de Matos Fontes (RJ), Odilon Ribeiro Coutinho (RN), Cid Furtado (RS), Euclides Triches (RS), Aniz Brada (SP), Athié Jorge Coury (SP), Franco Montoro (SP), Francisco Scarpa (SP), José Menck (SP), Paulo de Tarso Santos (SP), Plínio Soares de Arruda Sampaio (SP), Teófilo Ribeiro de Andrade (SP) e José Henrique Turner (SP) (COELHO, 2003).
4 Legislatura de 1946-1951: elegeram dois deputados (Arruda Câmara por Pernambuco e Manuel Vitor de Azevedo, por São Paulo). Na legislatura de 1951-1955: elegeram também dois (Arruda Câmara, e pelo Amazonas André Vidal de Araújo). No entanto, com o realinhamento partidário Antenor Mourão Bógea, eleito pela UDN no Maranhão, anunciou sua filiação ao PDC em 1954, acompanhado por outros deputados estaduais baianos. Portanto, o PDC contou com quatro cadeiras federais no final da legislatura.

5 Jacques Maritain foi um filósofo católico francês, cuja reinterpretação da filosofia tomista e suas ideias acerca do "humanismo cristão" e da Democracia influenciaram tanto o desenvolvimento da Democracia Cristã na Europa, quanto sua difusão na América Latina. Sobre a recepção das suas ideias no Brasil. Ver especialmente: MONTEIRO, Lorena. DRUMOND, André. A democracia na obra de Jacques Maritain e sua recepção pelos círculos católicos brasileiros. Tomo (UFS), v. 18, p. 43-70, 2011.

6 Alceu Amoroso Lima é um dos intelectuais, certamente o mais importante, do ressurgimento católico no Brasil. Sua trajetória reflete o desenvolvimento, os desdobramentos e as mudanças que ocorreram no campo do catolicismo no país.

7 O I Congresso da Democracia Cristã na América, realizado, em Montevidéu, em 1947, lançou as bases, a partir da "Declaração de Montevidéu", para a expansão dos movimentos democratas cristãos na América Latina.

8 Escola cepalina era o nome dado para aqueles que defendiam as teses da Comissão Econômica para a América Latina (CEPAL). As teses da CEPAL propunham a intervenção estatal na economia para alavancar o desenvolvimento dos países latino-americanos.

9 Ernani Maria Fiori (PL); Francisco Machado Carrion (PSD); Eloi José da Rocha (PSD); Armando Dias de Azevedo (PL); Carlos de Britto Velho (PL); Antônio Bottini (PL); Adroaldo Mesquita da Costa (PSD); Décio Martins Costa (PL); José Mariano de Freitas Beck (PTB); Adalberto Tostes (PL); Arthur Fischer (PSD); Bruno de Mendonça Lima (UDN); Romário Marques Machado (PRP); José Salgado Martins (UDN); Daniel Agostinho Faraco (PSD); Nicanor da Luz (PSD); Otto Belgio Trindade (PSD); Hugo Di Primio Paz (PRP); Elpídio Fialho (PSD); Mário Azambuja (PSD); Francisco Assis de Oliveira (PL); Albino Lenz (PL); Oscar Carneiro da Fontoura (PSD); Paulo Rache (UDN); Anor Butler Maciel (PRP); Raymundo João Cauduro (PSD); Theobaldo Neumann 
(PTB); Damaso Rocha (PSD); José Truda Palazzo (PL), dentre outros.

10 Cel. Américo Silveira D'ávila, João Silveira, Gercino Vieira, Ângelo Vitali, Carmelo Mário Faraco, Petrarco Callado, Washington Luiz do Valle Pereira, Giovani Paschoalini Faraco, Heitor Farias, Carlos Victor Gevaerd, Eduardo Mário Tavares, Júlio Vieira, entre outros. Ver especialmente: LENZI, Carlos Alberto Silveira. Partidos e políticos de Santa Catarina. Florianópolis, Ed. UFSC, 1983.

11 José Alexandre Zacchia era professor do Colégio Anchieta, e embora não fizesse parte do grupo das Congregações Marianas e da Ação Católica, era uma liderança católica de bairro, do movimento paroquial. Conforme SANSEVERINO, José Sperb. Entrevista cedida à autora, 2008 e FONSECA, Fernando Gay. Entrevista cedida a Hélgio Trindade, 2001.

\section{Bibliografia}

AMES, Barry. Os entraves da democracia no Brasil. Rio de Janeiro: Fundação Getúlio Vargas, 2003.

BENEVIDES, Maria Victoria de Mesquita. A UDN e o udenismo: ambiguidades do liberalismo brasileiro (1945-1965). Rio de Janeiro, Paz e Terra, 1981.

BUSETTO, Áureo. A Democracia Cristã no Brasil: princípios e práticas. São Paulo, UNESP, 2002.

CÁNEPA, Mercedes. Partidos e representação política: a articulação dos níveis estadual e nacional no Rio Grande do Sul (1945-1965). Porto Alegre, Editora da UFRGS, 2005.

COELHO, Sandro Anselmo. Democracia Cristã e populismo: um marco histórico comparativo entre o Brasil e o Chile. Revista de Sociologia e Política, n. 15, 67-82, nov. 2000.

COELHO, Sandro Anselmo. O Partido Democrata Cristão: teores programáticos da terceira via brasileira (1945-1964). Revista Brasileira de História, São Paulo, v. 23, n. 46, p. 201-228, 2003.

D'ARAÚJO, Maria Celina Soares. Sindicatos, carisma e poder: o PTB de 1945-1965. Rio de Janeiro, Ed. FGV, 1996.
FIGUEIREDO, Argelina; LIMONGI, Fernando. Executivo e Legislativo na nova ordem constitucional. Rio de Janeiro, FGV, 1999.

HIPPOLITO, Lúcia. De raposas e reformistas: o PSD e a experiência democrática brasileira, 1945-1964. Rio de Janeiro, Paz e Terra, 1985.

LENZI, Carlos Alberto Silveira. Partidos e politicos de Santa Catarina. Florianópolis, Ed. UFSC, 1983.

MAINWARING, Scott. Sistemas partidários em novas democracias: o caso do Brasil. Porto Alegre/Rio de Janeiro, Mercado Aberto/FGV, 2001.

MENEGUELLO, Rachel; LAMOUNIER, Bolívar. Partidos políticos e consolidação democrática: o caso brasileiro. São Paulo: Editora Brasiliense, 1986.

MENEGUELLO, Rachel. Partidos e governos no Brasil contemporâneo. São Paulo, Paz e Terra, 1998.

MENEGUELLO, Rachel; MAINWARING, Scott; POWER, Timoty. 2000. Partidos conservadores no Brasil contemporâneo. Quais são, o que defendem, quais são suas bases. São Paulo, Paz e Terra, 2000.

NETO, Amorim. SANTOS; Fabiano. A conexão presidencial: facções pró e antigoverno e disciplina partidária no Brasil. Dados, v. 44, n. 2. Rio de Janeiro, 2001.

SANSEVERINO, José Sperb. Entrevista. In: AXT, Gunter (Org.). Histórias de vida. Representações do judiciário. v. V. Memorial do Judiciário do Estado do Rio Grande do Sul; Porto Alegre, 2004.

SOUZA, Maria do Carmo Campello de. Estado e Partidos Políticos no Brasil (1930-1964). São Paulo, Alfa-Omega, 2003.

VIANNA, Werneck. O sistema partidário e o Partido Democrata Cristão. Caderno CEDEC, n. 1. São Paulo: Brasiliense, 1978.

VIANNA, L. Werneck. 1981. O sistema partidário e o Partido Democrata Cristão. In: FLEISCHER, C.V (Org.). Os Partidos Políticos no Brasil. Brasília: Edunb. 